\title{
Hypothalamic-Pituitary Functions in Patients with Idiopathic Pituitary Dwarfism*
}

\author{
Reiko DEMURA, Keiko JUJO, Kazue TAKANo, \\ EMI ODAGIRI, TADAo MAEDA, ToshIHIRo SUDA, \\ HiRoshi DEMURA aNd KAZUO SHIZUME
}

\author{
Dept. of Internal Medicine, Tokyo Women's \\ Medical College, Tokyo 162
}

\begin{abstract}
Synopsis
To investigate hypothalamic-pituitary functions and the primary site of the lesion in idiopathic pituitary dwarfism, various pituitary function tests, especially the pituitary hormone responses to the hypophysiotropic hormones were studied in 23 patients with idiopathic pituitary dwarfism. A few cases showed slight responses of GH to GH stimulation tests. Gonadotropin deficiencies were most frequently noted among pituitary hormones. The basal levels and the responses of plasma $\mathrm{LH}$ and FSH to LH-RH test were diminished markedly in all of the cases except in 5 cases with isolated GH deficiency. Responses of LH and FSH to LH-RH improved markedly after a long term administration of LH-RH for a period of one month in 2 patients with gonadotropin deficiency. As to TSH axis, half of the cases accompanied hypothyroidism. However, the responses of TSH to TRH were normal in all of the cases regardless of the thyroid function. The basal levels and the responses of plasma cortisol and 11-deoxycortisol to the rapid metopirone test were also impaired in about half of the cases. Basal levels of plasma prolactin were normal in all of the cases and the responses of prolactin to TRH were normal in cases with normal thyroid function, but slightly delayed in cases with hypothyroidism. It is concluded from the above observations that the incidences of various pituitary hormone deficiencies were quite high in this disorder and hypophysiotropic hormone deficiencies may cause pituitary hormone deficiencies. Therefore, it is suggested that the primary site of the lesion in this disorder might be at the hypothalamus.
\end{abstract}

Idiopathic pituitary dwarfism is not a rare disease but a few studies have been performed on the causes or hypothalamicpituitary functions of this disease. This study was undertaken to evaluate precise functions of various hypothalamic-anterior pituitary axes from a standpoint to clarify whether the primary site of the lesion is at the hypothalamus or the pituitary. Recently human growth hormone is available for therapeutic purposes, and we believe that an understanding of causes and hy-

\footnotetext{
Received for publication August 26, 1974.

* Aided by Grant-In-Aids of Japan Education Ministry (No. 831019) and Health Welfare Ministry.
}

pothalamic-pituitary functions of this disease will help a better use of $\mathrm{HGH}$.

\section{Materials and Methods}

Twenty three patients with idiopathic pituitary dwarfism, aged 8 to 33, were studied. Diagnosis were made according to the criteria of idiopathic pituitary dwarfism made by "Research Committee for Pituitary Disorders, Japanese Ministry of Health and Welfare (Shizume, 1974)". Two sets of siblings of familial isolated growth hormone deficiency were included.

Insulin tolerance test was performed by injecting $0.1 \mathrm{U} / \mathrm{kg}$ of regular insulin i. v. at fasting and blood samples were drawn before, and $15,30,45,60,90$, and $120 \mathrm{~min}$ after the injection for measurements of 
plasma GH and blood sugar. Glucagon-propranolol test was performed by simultaneous administration of $1 \mathrm{mg}$ of glucagon, i. m., and $1.0 \mathrm{~g}$ of propranolol orally. Blood samples were drawn before and at 30 min intervals for $3 \mathrm{hr}$ for measurement of $\mathrm{GH}$.

Arginine infusion test was performed by infusing $0.5 \mathrm{~g} / \mathrm{kg}$ of 1 -arginine as $10 \%$ solution in saline at fasting and blood samples were drawn before and $30,60,90$ and $120 \mathrm{~min}$ after an initiation of infusion for measurement of GH. Thyrotropin releasing hormone (TRH) test was performed by i. v. administration of $10 \mu \mathrm{g} / \mathrm{kg}$ of TRH at fasting and blood samples were drawn before and $15,30,45,60,90 \mathrm{~min}$ after the injection for measurements of plasma thyroid stimulating hormone (TSH) and prolactin (PRL). Luteinizing hormone releasing hormone (LH-RH) test was performed by injecting $100 \mu \mathrm{g}$ of LH-RH i. v. at fasting, usually combined with TRH for convenience, and blood samples were drawn at the same time intervals as TRH test for measurements of luteinizing hormone $(\mathrm{LH})$ and follicle stimulating hormone (FSH).

In three patients, two with gonadotropin deficiency and one with non-familial isolated GH deficiency, the same LH-RH tests were repeated after a period of one month with i. m. injection of $200 \mu \mathrm{g}$ of LH-RH daily. Rapid metopirone test was performed by oral administration of $1.0 \mathrm{~g}$ of metopirone at $9 \mathrm{a} . \mathrm{m}$. and blood samples were drawn at 2, 4, and $6 \mathrm{hr}$ after medication for measurements of plasma cortisol (F) and 11-deoxycortisol (S).

Plasma $\mathrm{GH}$ was measured by radioimmunoassay (RIA) using dextran coated charcoal method and NIH-GH was used as a reference standard. Plasma TSH was measured by RIA using h-TSH and antih-TSH serum supplied from the National Pituitary
Agency and Human Research Standard 68/38 from the Medical Research Council, London, was used as a standard. PRL was measured by RIA using V-L-S \#1 kit from the National Pituitary Agency. Plasma LH and FSH were measured by RIA using LH and FSH kits of Daiichi Radioisotope Laboratory. Plasma $\mathrm{F}$ and $\mathrm{S}$ were measured by RIA using anti. bodies made by ourselves with already reported methods (Demura, H., 1974). To assess thyroid function, measurements of serum thyroxine $\left(\mathrm{T}_{4}\right)$, triiodo. thyronine $\left(\mathrm{T}_{3}\right)$ and $\mathrm{T}_{3}$ resin sponge uptake and thyroidal ${ }^{131} I$ uptake were performed.

\section{Results}

The basal levels and maximal responses of plasma $\mathrm{GH}$ to various $\mathrm{GH}$ stimulation tests were shown in Figure 1. The fasting levels of $\mathrm{GH}$ were all less than $5 \mathrm{ng} / \mathrm{ml}$ and no or quite minimal responses were seen in most of the cases. However a few cases showed peak levels of more than $5 \mathrm{ng} / \mathrm{m} l$, one out of 23 cases in insulin tolerance test and 4 out of 18 in arginine infusion test and 3 out of 13 cases in glucagon-propranolol test.

Basal levels and maxial responses of TSH to TRH were shown in Figure 2. Nine patients had hypothyroidism with plasma $\mathrm{T}_{4}$ levels of less than $6 \mu \mathrm{g} / \mathrm{d} l$, and two of

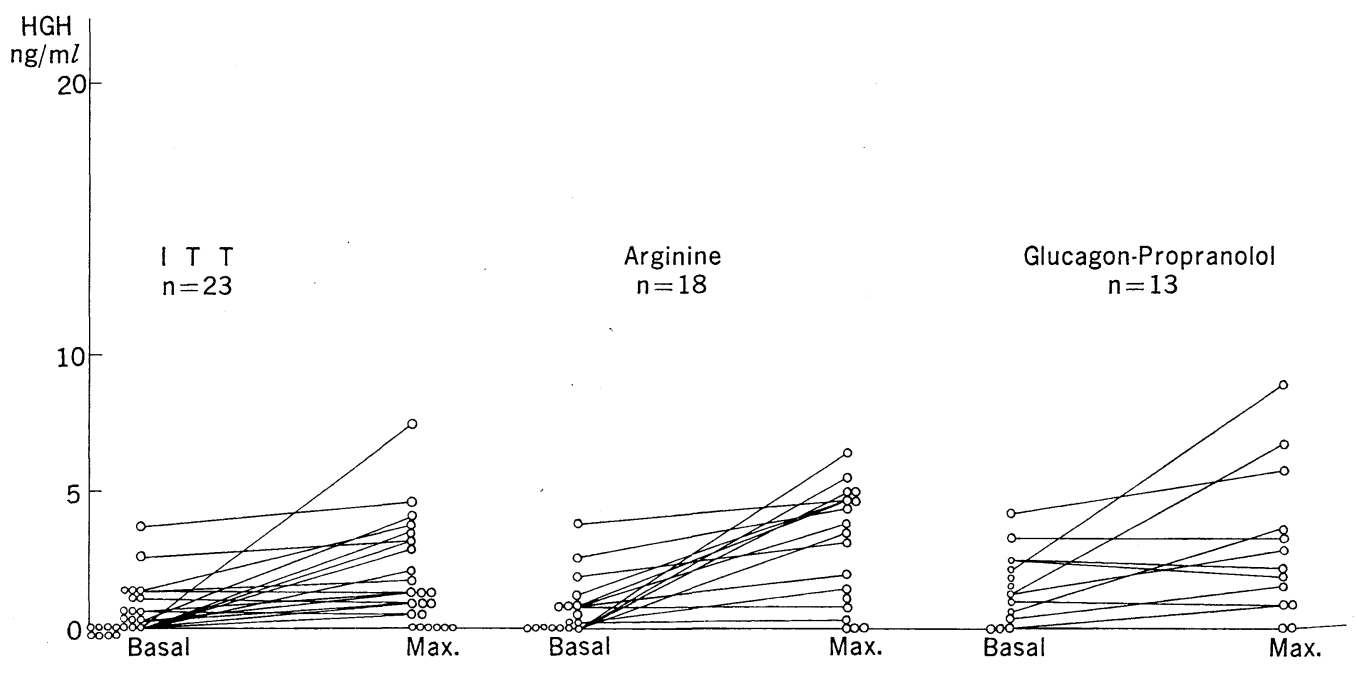

Fig. 1. Basal levels and maximal responses of $\mathrm{GH}$ to various $\mathrm{GH}$ stimulation tests. 


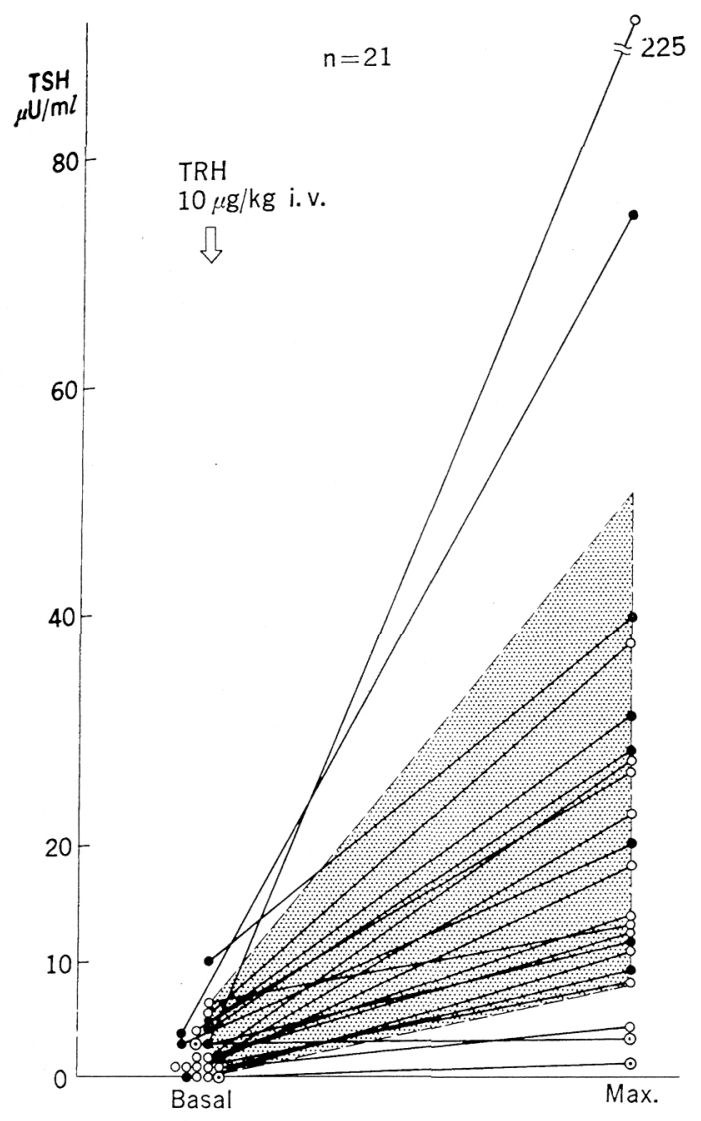

Fig. 2. Basal levels and maximal responses of plasma TSH to TRH test. Open circles indicated cases with normal thyroid function and closed circles indicated cases with hypothyroidism. Double circles indicated those with thyroid replacement therapy. Shaded area showed normal range.

them were placed on thyroid replacement therapy. Most of the cases except for those on thyroid replacement therapy showed normal responses of TSH of more than $8 \mu \mathrm{U} / \mathrm{m} l$ regardless of the thyroid function.

Basal levels and maximal responses of PRL to TRH were shown in Figure 3. The mean basal level of plasma PRL in 11 cases of pituitary dwarfism was $7.63 \mathrm{ng} / \mathrm{m} l$, while it was $7.30 \mathrm{ng} / \mathrm{m} l$ in normal children. Only one patient with hypothyroidism showed a high basal level of more than

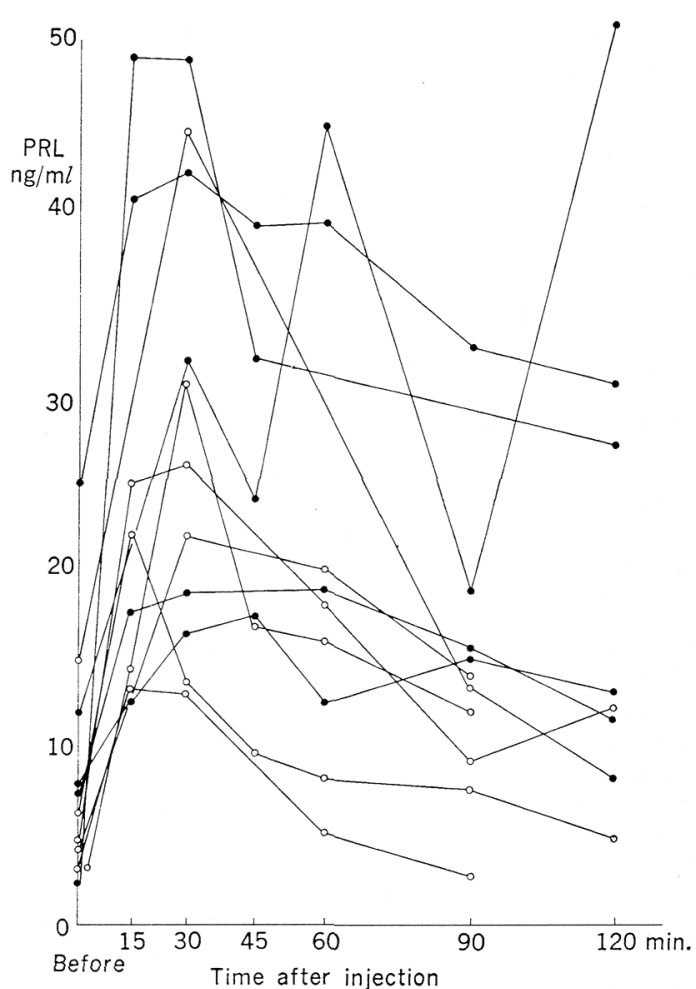

Fig. 3. Responses of PRL to TRH. Open circles indicated cases with normal thyroid function and closed circles indicated cases with hypothyroidism.

$20 \mathrm{ng} / \mathrm{ml}$. The responses of PRL to TRH were almost normal in cases with normal thyroid function, but somewhat bigger and delayed responses were noted in cases with hypothyroidism.

The basal levels and maximal responses of plasma $\mathrm{LH}$ and FSH to LH-RH were shown in Figure 4. Four cases including 3 cases of familial isolated $\mathrm{GH}$ deficiency, aged 12, 14, 15 and another boy of 13 years of age with non-familial isolated $\mathrm{GH}$ deficiency showed normal secondary sexual 

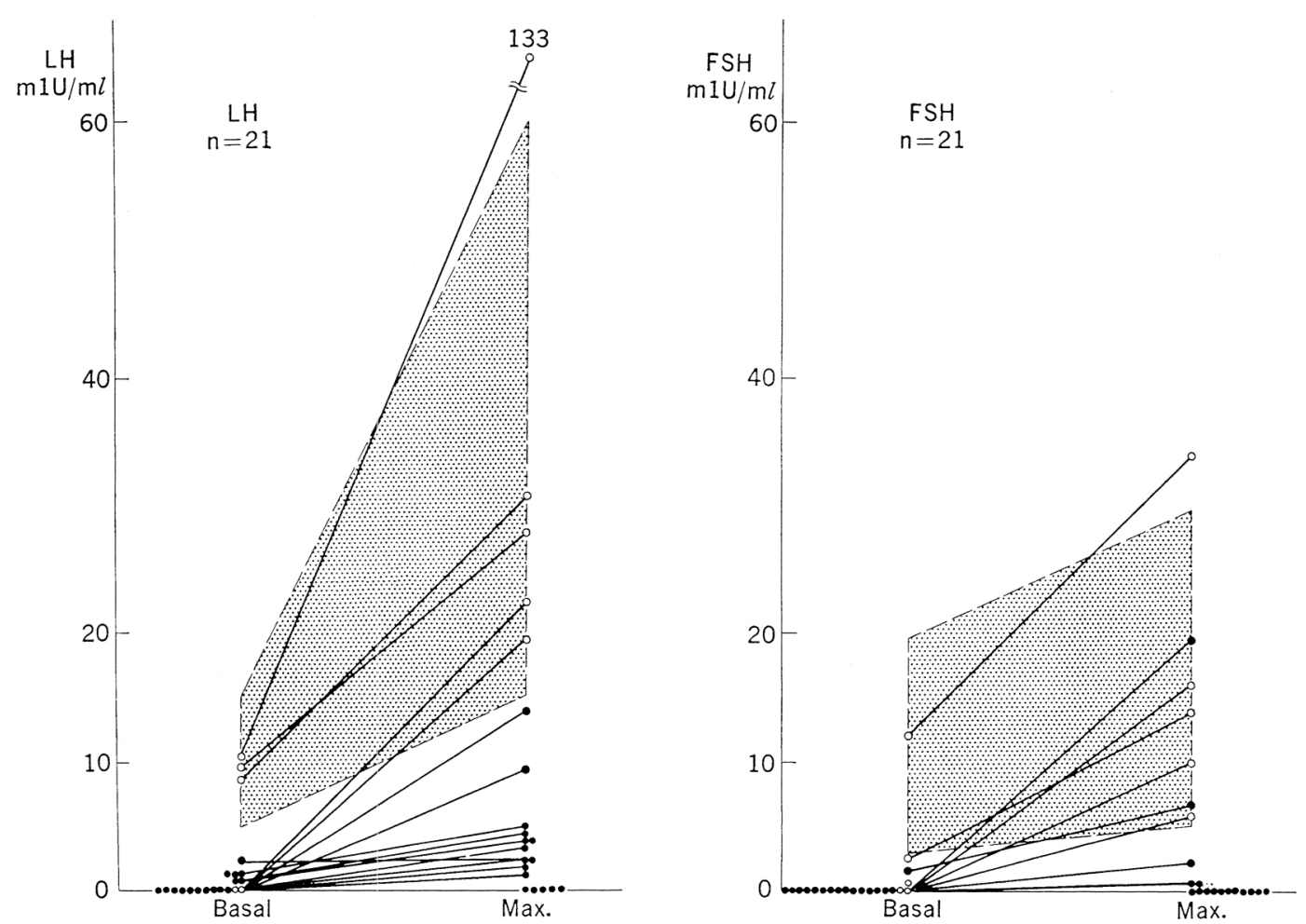

Fig. 4. Responses of plasma LH and FSH to LH-RH test. Open circles indicated cases with isolated $\mathrm{GH}$ deficiency and closed circles indicated cases with gonadotropin deficiency. Shaded areas showed normal ranges for children before adolescence.

characteristics, but the rest of the cases had no signs of sexual developement and patients after adolescence showed clinical signs of hypogonadism. Both of the basal levels and responses of $\mathrm{LH}$ and FSH to LH-RH were not detectable or minimal in all of the cases except in cases of isolated GH deficiency. On the contrary, the basal levels of $\mathrm{LH}$ were nomal in 3 and low in 2 out of 5 cases with isolated GH deficiency but the responses were grossly normal in all of the 5 cases. The basal levels of FSH were almost normal in 2 and low in 3 out of 5 cases, but the responses were normal in all cases with isolated GH deficiency similarly with the responses of $\mathrm{LH}$.

The responses of $\mathrm{LH}$ and FSH to LH-RH test after a continuous treatment with $\mathrm{LH}$ -
$\mathrm{RH}, 200 \mu \mathrm{g}$ daily, for a period of one month were shown in Figure 5. The responses of both $\mathrm{LH}$ and FSH were improved in two cases, Case 1 and 2, with gonadotropin deficiency, but remained the same in one case (Case 3) with isolated GH deficiency.

The responses of plasma $F$ and $S$ to rapid metopirone test were shown in Figure 6. None of the patients showed clinical signs of adrenocortical hypofunction, but 6 cases out of 15 showed subnormal levels of plasma $\mathrm{F}$ of less than $6 \mu \mathrm{g} / \mathrm{d} l$. The responses of both of plasma $F$ and $S$ were normal in patients with normal basal levels and impaired in those with subnormal basal levels.

Table 1 summarized the incidences of diminished pituitary functions, in consideration of basal function and reserve for six 


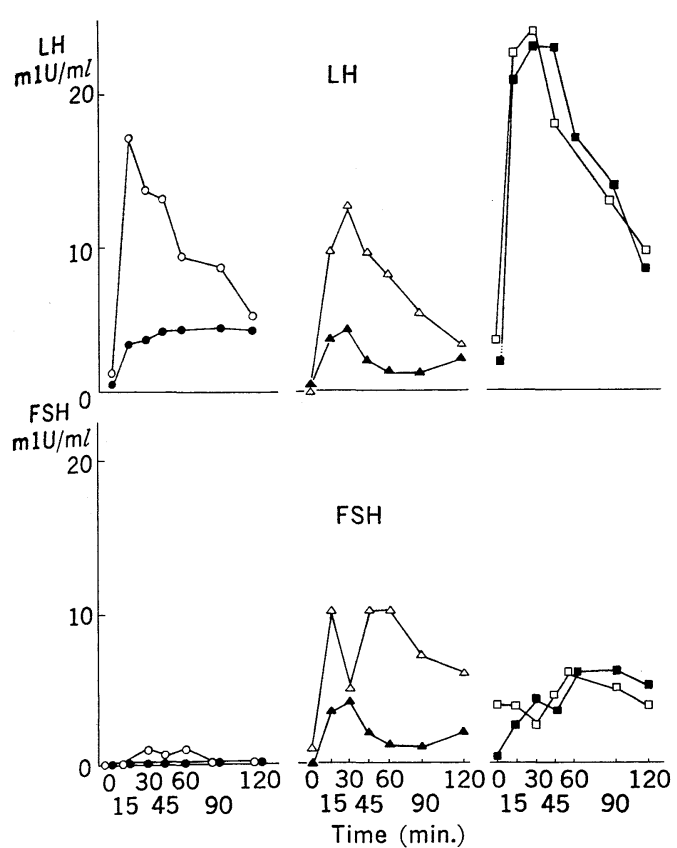

Fig. 5. Responses of LH and FSH to LH-RH test before and after one month of continuous administration of LH-RH. Closed marks indicated responses before and open marks indicated responses after treatment. Case 1, 2 and 3 from left to right.

anterior pituitary hormones. The incidences of diminished pituitary reserve were high for gonadotropin and ACTH, 70 and 50\% respectively, but only $5 \%$ for TSH and none for PRL. The discrepancy in the incidence of diminution between basal levels and reserves was most prominent in TSH axis, but no discrepancies were seen in the rest of the axes.

\section{Discussion}

One of the three main criteria of idiopathic pituitary dwarfism made by "Research Committee for Pituitary Disorders" (Shizume, 1974) is that the maximal responses of $\mathrm{GH}$ to 2 different $\mathrm{GH}$ stimulation tests did not exceed $5 \mathrm{ng} / \mathrm{ml}$. Nevertheless, we noted a few cases had GH responses of more than $5 \mathrm{ng} / \mathrm{m} l$. These cases with the minimal responses still had $\mathrm{GH}$ deficiency and they responded very well to GH therapy. Glucagon-propranolol test is a preferable test to find a minimal pituitary reserve than insulin tolerance test (Demura et al., 1974 a).

The primary site of the stimulation of $\mathrm{GH}$ by insulin tolerance test, glucagon-propranolol and most of the other kinds of GH stimulation tests has not been clearly demonstrated. The $\mathrm{GH}$ reserve obtained by these tests may represent the integral functions of the hypothalamic-pituitary axis. It will be difficult to tell a primary site of the lesion in a hypothalamic-pituitary axis untill growth hormone releasing factor is available.

It was clearly demonstrated that diminished pituitary functions other than $\mathrm{GH}$ characterized the features of idiopathic pituitary dwarfism. Diminished pituitary gonodotropin reserve was most frequent and about $80 \%$ in the present series. Actually all of the cases with idiopathic pituitary dwarfism except isolated GH deficiency had markedly diminished pituitary gonadotropin

Table 1. Incidences of diminished pituitary functions

\begin{tabular}{lcccccc}
\hline \hline & Pituitary hormones & GH & LH, FSH & TSH & ACTH & PRL \\
Incidences & & & & & & \\
\hline Basal secretion & No. of hypo/total & $23 / 23$ & $18 / 21$ & $9 / 21$ & $6 / 15$ & $0 / 11$ \\
& $\%$ & $(100)$ & $(85)$ & $(43)$ & $(40)$ & $(0)$ \\
\hline Pituitary reserve & No. of hypo/total & $23 / 23$ & $17 / 21$ & $1 / 19^{*}$ & $8 / 15$ & $0 / 11$ \\
& $\%$ & $(100)$ & $(71)$ & $(5)$ & $(53)$ & $(0)$ \\
\hline
\end{tabular}

* This number did not include cases with thyroid replacement therapy. 

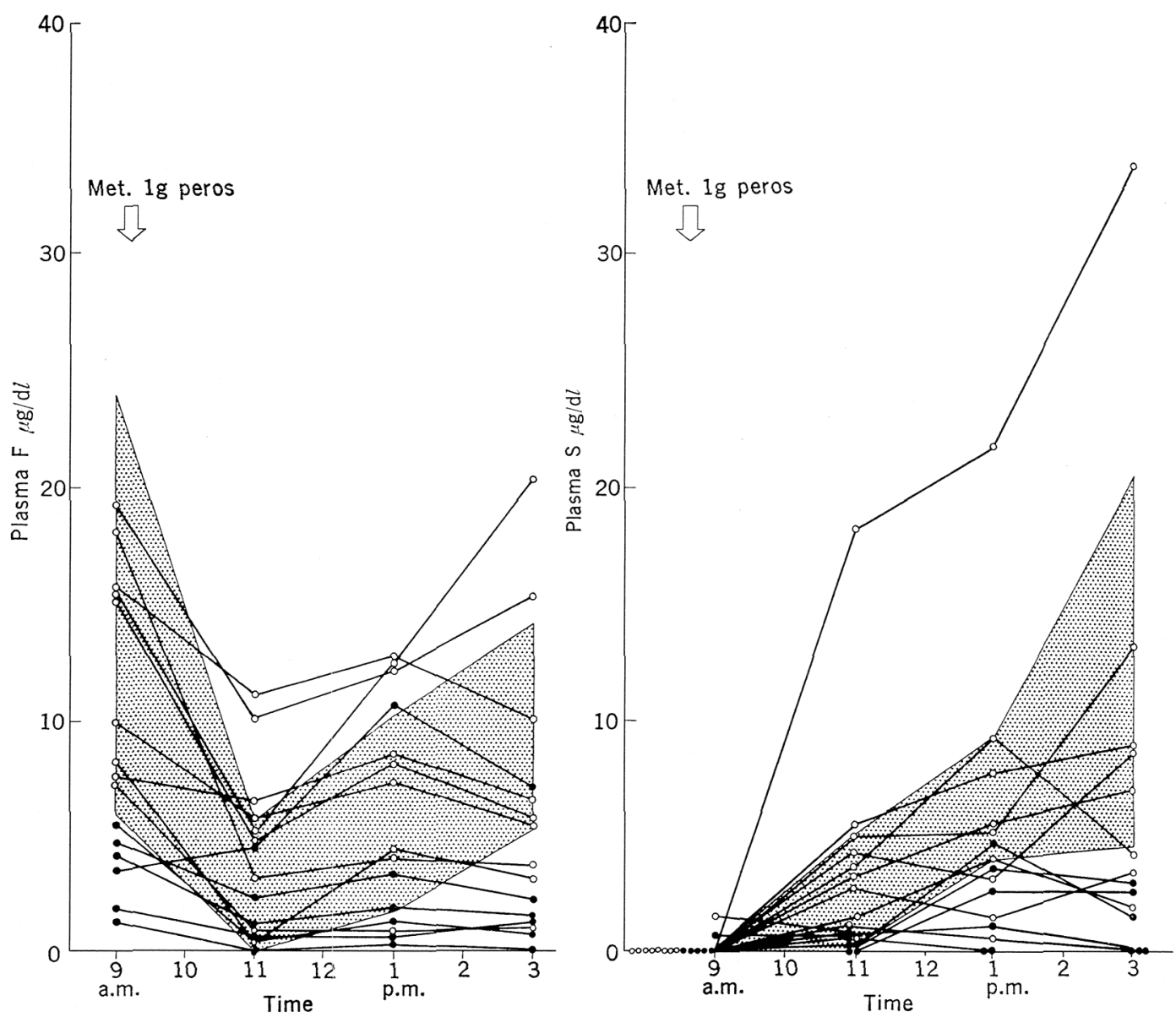

Fig. 6. Basal levels and responses of plasma $\mathrm{F}$ and $\mathrm{S}$ to rapid metopirone test. Open circles indicated cases with normal basal levels of plasma $F$ and closed circles indicated cases with plasma $\mathrm{F}$ of less than $6 \mu \mathrm{g} / \mathrm{d} l$. Shaded areas showed normal ranges.

reserve and hypoganadism. An improvement in the responses of pituitary gonadotropin after long term administration of LHRH in 2 cases with gonadotropin deficiency may indicate the existence of functioning pituitary gonadotrophs and lack of an appropriate releasing hormone stimulus. Therefore, hypothalamic disorder was more considerable than pituitary dysfunction as to gonadotropin deficiency.

As to hypothalamic-pituitary axis of TSH, the situation was more clear. Normal responses to TRH in cases with hypothyroidism indicated that hypothyroidism seen in this disorder was hypothalamic hypothyroidism. Several investigators (Costom et al., 1971 ; Foley et al., 1972 a) also reported the same results and concluded the hypo. thalamic origin of hypothyroidism associated with idiopathic pituitary dwarfism. Therefore, hypophysiotropic hormone deficiencies were thought to be responsible for both of TSH and gonadotropin deficiencies and the differences in the responses of TSH to TRH and gonadotropin to LH-RH may indicate different sensitivities of pituitary thyrotrophs and gonadotrophs to their hypophysiotropic hormones. 
As to the hypothalamic-pituitary axis of the hypothalamo-pituitary-adrenal system, it is difficult to decide a primary site of the lesion in this system. An availability of clinical application of corticotropin releasing factor (CRF) might be helpful for elucidation of this problem in future.

As to PRL secretion, a hypothalamicpituitary axis was thought to be grossly normal. Slightly bigger and delayed responses than normal seen in cases with hypothyroidism may be considered as a modification by thyroid hormone deficiency. Hyperresponse of PRL to TRH were reported in patients with primary hypothyroidism (Bowers et al., 1973; Demura, et al., $1974 \mathrm{~b}$ ) and prolaction releasing factor inhibiting factor (PIF) deficiency in this situation was proposed as one of the possible causes. Hyperresponse or delayed response of PRL to TRH in patients with idiopathic pituitary dwarfism with hypothyroidism were reported (Foley et al., 1972 b; Kaplan et al., 1972). On the other hand, normal responses of PRL to TRH in patients with pituitary dwarfism were reported by others (Guyda et al., 1973; Underwood et al., 1972). Tolis et al. (1973) reported that an analysis of basal levels and responses of PRL to TRH or chlorpromazine would be helpful to estimate the site and the grade of hypothalamic-pituitary involvement. From our present results of PRL secretion, no direct evidence of hypothalamic involvement was demonstrated. At least pituitary reserve of PRL was not diminished in any of the cases.

From the present observations, deficiencies of various pituitary hormones were clearly demonstrated except for PRL. Hypophysiotropic hormone deficiencies were concluded for impaired gonadotropin and TSH secretions. These facts may strongly suggest that the primary site of the lesion is at the hypothalamus in idiopathic pituitary dwarfism.

\section{Acknowledgement}

This study was partly supported by a research grant for "Specific Diseases" of the Japanese Ministry of Health and Welfare, and by a research grant from the Japanese Ministry of Education (No. 837019).

\section{References}

Bowers, C. Y., H. G. Friesen and K. Folkers (1973). Biochem. Biophy. Res. Commun. $51,512$.

Costom, B. H., M. M. Grumbach and S. L. Kaplan (1971). J. Clin. Invest. 50, 2219. Demura, H. Radioimmunoassay (edited by M. Irie), Kodanshya Scientific, Tokyo, p. 319 (1974). (In Japanese)

Demura, R., K. Ichikawa, K. Takano and K. Shizume (1974 a). Clinical Endocrinology 22, 63. (In Japanese)

Demura, R., S. Saisu, K. Takano, K. Jujo, E. Odagiri, T. Maeda, T. Suda, H. Demura and K. Shizume (1974 b). Clinical Endocrinology 22, 1167. (In Japanese)

Foley, T. P. Jr., J. Owings, J. H. Hayford and R. M. Blizzard (1972 a) J. Clin. Invest. 51, 431.

Foley, T. P. Jr., L. S. Jacobs, W. Hoffman, W. H. Daughaday and R. M. Blizzard (1972 b). Ibid. 51, 2143.

Guyda, H. J. and H. G. Friesen (1973). Pediat. Res. 7, 534.

Kaplan, S. L., M. M. Grumbach, H. G. Friesen and B. H. Costom (1972). J. Clin. Endocr. 35, 825.

Shizume, K. (1974). Japan Medical Journal 2599, 102. (In Japanese)

Tolis, G., M. Goldstein and H. Friesen (1973). J. Clin. Invest. 52, 783.

Underwood, L. E., R. L. Hintz, D. R. Clemmons, S. J. Voina, R. W. Turkington and J. VanWyk (1972). Pediat. Res. 6, 348. 